\title{
Aspectos subjetivos do morar e trabalhar na mesma comunidade: a realidade vivenciada pel a agente comunitário de saúde
}

Tatiana de Andrade Jardim ${ }^{1}$ Selma Lancman ${ }^{2}$

JARDIM, T.A.; LANCMAN, S. Subjective aspects of living and working within the same community: the realities experienced by community healthcare agents. Interface -

Comunic., Saúde, Educ., v.13, n.28, p.123-35, jan./mar. 2009.

Community health agents (CHAs) provide links between communities and the health system within the Family Health Program (FHP) and are the only workers required to live in the community where they work. They maintain direct, continuous and uninterrupted community contact. This paper discusses the process of constructing and maintaining agents' credibility in relationships with their community and the subjective factors resulting from living and working congruently. The methodology proposed for work psychodynamics was used among CHAs in Pirituba, State of São Paulo. It was concluded that agents experience embarrassing situations during their work, consequent to belonging to the same community within which they play their professional role. The way that the FHP functions and the precarious situation of other levels of the health system are sources of additional suffering. This porosity between living and working in the same community excessively exposes the workers, with high contamination of their non-working time.

Key words: Community health agent. Workers' health. Working conditions. Mental health and work. Qualitative research.
O Agente Comunitário de Saúde (ACS) é o elo entre comunidade e sistema de saúde no Programa Saúde da Família (PSF), sendo o único trabalhador que obrigatoriamente reside na comunidade onde trabalha. Seu trabalho é pautado no contato direto, contínuo e ininterrupto com a comunidade. Este artigo discute o processo de construção e manutenção da credibilidade dos agentes nas relações com a comunidade e os fatores subjetivos resultantes da congruência entre morar e trabalhar. Utilizou-se a metodologia proposta em Psicodinâmica do Trabalho, com ACS de Pirituba/SP. Concluiu-se que os agentes vivenciam constrangimentos no trabalho decorrentes de pertencerem à mesma comunidade na qual desempenham seu papel profissional e que o funcionamento do PSF e a precariedade dos demais níveis do sistema de saúde são fonte de sofrimento adicional. Essa porosidade entre trabalhar e morar na mesma comunidade expõe excessivamente os trabalhadores e há elevada contaminação do tempo do não trabalho.

Palavras-chave: Agente Comunitário de Saúde. Saúde do trabalhador. Condições de trabalho. Saúde mental e trabalho. Pesquisa qualitativa.

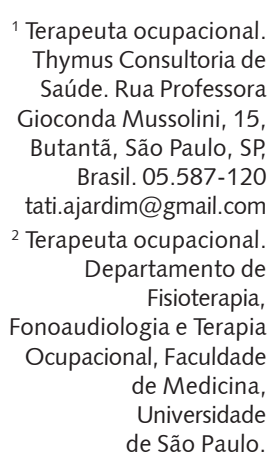




\section{Introdução}

\section{O Agente Comunitário de Saúde e o Programa Saúde da Família}

O Programa Saúde da Família (PSF) objetiva promover a saúde e garantir melhorias na qualidade de vida dos sujeitos, direcionando-se não somente para a cura e prevenção de doenças, mas, sobretudo, para a valorização e ênfase do papel dos indivíduos no cuidado com sua saúde, de sua família e da comunidade, por meio do desenvolvimento de vínculos de corresponsabilidade (Brasil, 2006).

O Agente Comunitário de Saúde (ACS) é o trabalhador de destaque nessa proposta de atenção, e integra a Equipe Saúde da Família trabalhando em área geograficamente delimitada, cujos contornos são determinados pela quantidade de pessoas (ou famílias) que deve atender (parâmetros: 2.500 a 4.500 pessoas por equipe de saúde, e 450 a 750 pessoas por ACS - microárea).

O ACS se configura como elo entre comunidade e equipe de saúde, por ser o profissional que está primordialmente realizando as visitas domiciliares. Além disso, é o primeiro contato dos serviços de saúde pública com a comunidade local advindo da iniciativa dos programas de saúde.

O ACS trabalha em uma microárea de sua comunidade. Enfatiza-se 'sua comunidade', pois além de trabalhar nela, o ACS é sujeito da mesma. Ou seja, deve morar na região e, para além do ato de residir, ele pertence a essa comunidade.

\section{O trabalho do Agente Comunitário de Saúde}

Segundo o Ministério da Saúde, as atribuições do agente estão relacionadas a um aspecto estruturante: o papel de educador como um agente de mudança naquela comunidade (Brasil, 2006).

Spiri (2006), Lunardelo (2004), Nunes et al. (2002), Silva e Dalmaso (2002) e Tomaz (2002) concordam na afirmação de que o ACS é um sujeito que emerge da comunidade e se integra às equipes de saúde, sem bagagem técnica específica, e trabalha por meio do diálogo com a comunidade buscando conscientizar e ser um agente educador.

O papel de agente transformador é considerado como algo possível pelo agente, na medida em que realiza as visitas domiciliares, conhece as reais necessidades daquela comunidade e faz a mediação desta com a equipe e o sistema de saúde. Também tem papel de anteparo do sistema de saúde e, por vezes, devido a essa condição, enfrenta resistências da população e dificuldades de relacionamento.

O domicílio não é um território público e o seu acesso nem sempre é evidente e fácil; portanto, para realizar seu trabalho, o agente deve estabelecer vínculo e relações de confiança com a comunidade. O agente somente adentra e conhece a intimidade dos usuários com permissão da família, devendo sempre preservar essa privacidade (Lunardelo, 2004).

Lunardelo (2004) e Nunes et al. (2002) pontuam que o contato com a população gera intenso envolvimento pessoal e desgaste emocional para o agente.

A onipotência e a frustração permeiam a subjetividade de um agente social, que mantém profunda relação de pertença com seu espaço: o espaço em que vive é o mesmo onde atua, as pessoas da sua realidade social são as mesmas para quem dirige as suas ações de cuidado. (Spiri, 2006, p.8)

Outros apontamentos desses autores referem que há ambiguidade de relações, sentimentos e emoções vivenciadas pelo agente, fruto dessa relação atípica de trabalho. Geram, no ACS, sentimentos ambíguos, de prazer e sofrimento: o constante contato com a população; entrada em seus domicílios e vida privada; envolvimento; conhecimento das demandas e impossibilidades de ação, quando constata os limites do setor de saúde.

A relação de igual que o agente comunitário estabelece com a comunidade, com uma proximidade física, intelectual e social das famílias e dos indivíduos, repercute em seu trabalho, com a criação de vínculos, a compreensão do ser e o entendimento da 
${ }^{3}$ Os termos usuário e cliente referem-se à população adscrita àquele determinado agente. complexidade do meio onde vivem estas pessoas. Nessa aproximação e envolvimento do ACS com as famílias, há transposição dos problemas e das misérias humanas. Eles se envolvem, se vêem naquela ocorrência e acabam sofrendo com isso. (Lunardelo, 2004, p.107)

As consequências, na vida do agente, decorrentes do fato de morar no próprio bairro, na mesma microárea, frequentar as residências dos usuários ${ }^{3}$ e ser facilmente encontrado é um campo a ser questionado e mais explorado.
A entrada no mundo familiar traz inevitavelmente consigo a intimidade das pessoas, o seu mundo privado, e, com ele, novas construções relacionais permeadas de significados e de sentimentos. [...] Pode-se pensar que esse modelo relacional condiciona, então, a excessiva valorização dos aspectos afetivos da relação desenvolvida pelos ACS com os moradores, bem como a ênfase que é colocada pelos usuários do PSF em conteúdos ligados à vida pessoal dos agentes, chegando por vezes ao extremo de exercerem um controle social sobre as suas vidas privadas. (Nunes et al., 2002, p.1644-5)

O trabalho do agente traz diversas novidades à atenção primária em saúde e aos próprios trabalhadores, destacando-se o fato da obrigatoriedade de morarem e trabalharem na mesma comunidade. Esta dupla inserção na comunidade os leva a terem duplo papel: o de ser simultaneamente agente e sujeito. Tal relação cria uma porosidade entre o trabalhar e o viver na comunidade, ou seja, o agente não possui o distanciamento entre o ato de trabalhar e de morar, visto que acontecem nos mesmos espaços físicos e na relação com a mesma comunidade. Assim, a forma como o trabalho está organizado pode ser uma fonte de sofrimento psíquico a esse trabalhador, podendo esse sofrimento se tornar patogênico.

\section{A centralidade do trabalho à luz da Psicodinâmica do Trabalho}

Autores como Dejours (2004), Lancman e Jardim (2004) e Molinier (2004) estudam a centralidade do trabalho enquanto fator de construção psíquica, considerando sua importância nas relações indivíduo-sociedade e na constituição do próprio sujeito.

O trabalho é mais do que o ato de trabalhar, vender força de trabalho em troca de remuneração. $\mathrm{O}$ trabalho assume papel central na constituição identitária e possui implicação direta nas diversas formas de inserção social dos indivíduos. $O$ trabalho pode ser visto como fundamental na constituição de redes de relações sociais, pertinência a grupos, e trocas afetivas e econômicas, bases da vida cotidiana; e também possui função psíquica, por ser um dos alicerces da constituição do sujeito e sua rede de significados.

A constituição da identidade é compreendida como um processo que se desenvolve ao longo da vida do indivíduo e que está vinculada à noção de alteridade. É a partir do 'olhar do outro' que nos constituímos como sujeitos; é na relação com o outro que nos reconhecemos, num processo de busca de semelhanças e diferenças. São as relações cotidianas que permitem a construção da identidade individual e social e é, a partir de trocas materiais e afetivas, que constitui sua singularidade, em meio a diferenças (Lancman, Jardim, 2004). A Psicodinâmica do Trabalho (PDT) entende que, na vida adulta, o espaço do trabalho será privilegiado para trocas, aparecendo como mediador central da construção, 
desenvolvimento e complementação dessa identidade individual. Assim, o trabalho tem fundamental importância para a constituição da vida psíquica (Dejours, 2004).

O trabalho permite, também, o confronto entre mundo externo e interno do trabalhador. O mundo objetivo, com suas lógicas, desafios, regras e valores entrará em conflito com a singularidade do trabalhador, fazendo com que o confronto entre relações e organizações do trabalho versus mundo interno e subjetivo do trabalhador seja gerador de sofrimento psíquico.

Nesse sentido, Dejours (2004) e Molinier (2004) definem que identidade é uma espécie de armadura psíquica que protege o indivíduo dos constrangimentos da organização, resultado de um trabalho de unificação psicológica que produz um sentimento de estabilidade, continuidade e integração do indivíduo. Mas essa armadura será sempre reconfirmada e reconfigurada pelo olhar do outro, na dialética eu e o outro. Assim, a produção da saúde é, nesse sentido, intersubjetiva.

Para Dejours (2004), a construção identitária no trabalho está ainda relacionada a dois processos de reconhecimento: julgamento estético e de utilidade. Este último é realizado pelos níveis hierárquicos aos quais o trabalhador está submetido, incluindo clientes. É ligado a critérios de resolutividade e eficácia. Já o julgamento estético é aquele realizado pelos pares, que conhecem tanto as dificuldades quanto as soluções que os trabalhadores vivenciam para alcançar os resultados estipulados pela organização. Esse julgamento permite dar visibilidade à engenhosidade dos trabalhadores - fruto da inteligência desenvolvida no trabalho, seus esforços para fazer o trabalho acontecer, apesar dos constrangimentos, e, por vezes, dos fracassos vivenciados.

Se o mundo do trabalho é gerador de sofrimento, na medida em que confronta as pessoas com desafios externos, também é a oportunidade central de crescimento e desenvolvimento psicossocial do adulto. O trabalho pode levar ao sofrimento e adoecimento ou se constituir numa fonte de prazer e desenvolvimento humano do indivíduo. Assim, fica evidente que o trabalho e as relações que nele se originam nunca são um espaço de neutralidade subjetiva ou social.

Ao se configurar como elemento central na construção identitária, o trabalho permeia e influencia outras esferas da vida do sujeito, mesclando o tempo da jornada de trabalho propriamente dita com o tempo do não trabalho - o que Dejours (2004) denomina contaminação do tempo do não trabalho.

Ao se considerar a obrigatoriedade da congruência entre local de trabalho e moradia do agente, atrelada às dificuldades que o trabalhador encontra para realizar seu trabalho a contento, devido a limitações do funcionamento do sistema de saúde, pode-se questionar tal obrigatoriedade como fonte adicional de sofrimento psíquico, decorrente da indiferenciação entre o ato de morar e o de trabalhar no cotidiano e nas relações sociais do ACS.

Acrescenta-se ao questionamento acima, outro aspecto: o envolvimento afetivo e ininterrupto que esse vínculo com a comunidade traz para o agente em relação ao seu cliente, acrescido do testemunho das consequências que a falta de resolução das situações de saúde dos usuários provocam neles, agentes.

Assim, objetivamos, com este artigo, dar visibilidade aos aspectos subjetivos do trabalho dos agentes, no que tange ao morar e trabalhar na mesma comunidade, contribuindo para o conhecimento dessa realidade profissional; e verificar como essa organização do trabalho impacta na saúde mental desses trabalhadores. É nosso objetivo, ainda, compreender a engenhosidade e inteligência desenvolvidas no trabalho para fazê-lo acontecer e, também, as estratégias adotadas por esses trabalhadores para, de um lado, viabilizar o trabalho, e, de outro, diminuir o sofrimento gerado pela peculiaridade da relação trabalhar e morar no mesmo território.

\section{Material e método de pesquisa}

Este artigo é parte da pesquisa 'Avaliação do Programa de Expansão e Consolidação da Saúde da Família - PROESF - para desenvolvimento de estudos avaliativos 3 - SUDESTE', decorrente de solicitação do Ministério da Saúde (proposta e resultados acessíveis em Cedec, 2006). Objetivou-se compreender os fatores que compõem a complexidade da atenção básica no Programa Saúde da Família/Região Sudeste. 
Pesquisadores da Universidade de São Paulo investigaram a hipótese de que o processo de trabalho do PSF apresenta singularidades e inovações em relação ao trabalho usualmente desenvolvido na atenção básica, instaurando uma complexidade que interfere diretamente na qualidade da implantação do Programa. Para tanto, foram constituídas três equipes de pesquisa, cada qual utilizou uma abordagem: Ação em Psicodinâmica do Trabalho, Análise da Organização do Trabalho e Ação Ergonômica do Trabalho. Entre os achados oriundos da PDT, compõem este artigo: os resultados referentes aos aspectos morar e trabalhar na mesma comunidade, e impossibilidade de resolução dos problemas que os agentes vivenciam no seu trabalho.

Dada a complexidade do objeto e dos objetivos da PDT, podemos dizer que esta se inscreve no campo da investigação qualitativa e, em especial, da pesquisa-ação. Essas buscam apreender a percepção, compreensão e participação dos sujeitos diante dos problemas investigados, e consideram, também, a importância dos aspectos relacionais presentes no fenômeno.

A PDT preconiza a compreensão dos aspectos subjetivos do trabalho a partir de grupos de reflexão e da criação de um espaço público de discussão, entendidos como espaço privilegiado para a transformação de vivências individuais em reflexões coletivas. O método define-se com uma clínica do trabalho, onde, por meio da escuta coletiva dos trabalhadores, busca-se elucidar aspectos menos visíveis do trabalho e, ainda, favorecer a reapropriação, por parte dos trabalhadores, da engenhosidade e inteligências desenvolvidas para fazer o trabalho acontecer a despeito dos constrangimentos vivenciados. Entre os objetivos de uma ação em PDT também estão: compreensão das relações sofrimento-prazer no trabalho, e estratégias defensivas individuais e coletivas desenvolvidas frente ao sofrimento vivenciado no trabalho, de modo que seja um fator de desenvolvimento identitário, de realização de si e de promoção de saúde. A reapropriação é fundamental para desencadear, entre os trabalhadores, uma ação transformadora do seu fazer e das relações que estabelecem com aquilo que produzem.

As etapas constitutivas do método da PDT são: pré-pesquisa; reconfiguração da demanda; apresentação do projeto aos trabalhadores e identificação de voluntários; grupos de reflexão; restituição e validação do relatório preliminar redigido pelos pesquisadores. Sequencialmente, o relatório final, segundo acordo prévio, torna-se material público.

A pesquisa foi realizada na sub-região administrativa de Pirituba, município de São Paulo, e a escolha deu-se a partir de dados sociodemográficos e de alguns dos resultados do PSF, tais como: tempo de implantação; presença de equipes completas, e diversidade de perfil epidemiológico.

Para a realização das etapas previstas no método, constituiu-se um grupo gestor, composto por pesquisadores, coordenadores e gerentes das unidades saúde da família Jardim Cidade Pirituba, Moinho Velho e Santo Elias.

Em seguida, fez-se a apresentação da proposta para o coletivo de trabalhadores, sendo acordado o caráter voluntário da participação e o sigilo. Este consiste no acordo coletivo de que os assuntos tratados no grupo não seriam conversados em outros locais de trabalho, sequer com outros colegas, garantindo-lhes a segurança de que tais assuntos não seriam públicos antes da validação final do relatório, nem identificariam os participantes.

Dada a impossibilidade de todos participarem, os trabalhadores definiram os participantes, resguardando o critério de voluntariado e de representatividade de todas as Unidades envolvidas.

O grupo foi realizado entre maio e agosto de 2005, e composto de 16 agentes, de ambos os sexos, sem limite de idade ou tempo de trabalho no PSF, e três pesquisadores nas funções de coordenação e registro das sessões. Todos os participantes assinaram o termo de consentimento livre e esclarecido, previsto pela comissão de ética da FMUSP.

A heterogeneidade do grupo foi obtida com a participação de, pelo menos, um membro de cada equipe de saúde da família, representando o coletivo de trabalhadores dessa região.

O processo grupal proposto pela PDT não segue um roteiro preestabelecido, e a condução dos pesquisadores destina-se a: organizar as discussões, promover a participação de todos, solicitar esclarecimentos, pontuar aspectos relevantes, e registrar o material clínico que será restituído aos trabalhadores posteriormente. O processo grupal é iniciado, metodologicamente, pela reconfiguração da demanda: apresentação dos objetivos iniciais que trazem os pesquisadores a campo e busca de 
compreender e rever esses objetivos a partir da demanda dos trabalhadores, e o que os mobilizava como assuntos a serem discutidos.

Ao término dos encontros, os pesquisadores produziram o relatório e houve a sessão de validação pelo grupo, com duração de quatro horas. Os encontros aconteceram durante a jornada de trabalho e foram, inicialmente, acordados com os participantes e chefias, inclusive o período para elaboração do relatório e a sessão de validação. Cada participante recebeu um documento contendo o relatório final do grupo e uma breve introdução contextualizando a pesquisa e o método desenvolvido.

\section{Resultados}

\section{Processo de construção da credibilidade e as relações de trabalho: ACS e usuário}

A credibilidade no trabalho que desenvolve o ACS é um aspecto fundamental para a concretização do mesmo, sendo um processo dinâmico e cotidiano de construção e reconstrução. Sem essa credibilidade não há confiança por parte da comunidade, e o trabalho do agente fica impossibilitado de acontecer.

Tal credibilidade tem o sentido de criar relações de confiança com os usuários para que recebam os agentes, abram suas casas, contem seus problemas pessoais, e que as demandas sejam solucionadas ou encaminhadas, assegurando a continuidade da relação saudável agente-comunidade.

Os ACS referem que o primeiro contato com a comunidade não foi fácil. Vivenciaram, diversas vezes, grande resistência ao contato direto, ao entrarem nas casas." Os ACS não sabem o que irão encontrar, pois cada casa é uma surpresa; precisam ser recebidos de fato, senão não há acesso à família, não há trabalho. [...] a população nem sempre abre a porta, é necessário criar uma estratégia mútua de confiança" ${ }^{4}$; "Foi assustador, o vizinho não abria o portão, fingia que não estava em casa. A maioria não abria a porta por falta de confiança. Foi de chorar! Com o desenvolvimento do trabalho ficou mais fácil!".

Referem que com a aproximação e constância nas visitas aprenderam a construir a credibilidade necessária para realizar o trabalho. Relatam, ainda, a surpresa que esse contato trouxe, pois, mesmo morando na comunidade, não conheciam a realidade de muitas famílias, apesar da relação de proximidade que tinham como vizinhos. Esses vizinhos, por vezes, apresentam maior resistência à entrada dos agentes, pois "nem sempre querem que você saiba o que se passa", sobretudo quando estão em situações desfavoráveis financeiramente. "Estão confiando mais na gente. Bom dia, sou seu ACS! - falo sempre para lembrarem. A gente criou um jeitinho de cada um, pra sempre entrar na casa"; "Eu moro aqui o tempo todo e não tinha noção do que era minha comunidade".

Uma das formas de conquistarem a credibilidade é assegurar aos usuários que as informações obtidas não serão utilizadas para fins alheios ao do trabalho do PSF, sequer serão divulgadas para outros moradores: "Muitos respondem fumando maconha. A gente não dedura ninguém. Não chama a polícia".

Ao se relacionarem com a comunidade, referem entrar em contato com grande diversidade de situações. O contato com as famílias revela a eles situações precárias de ordem financeira e emocional, e uma questão evidencia-se aos agentes: Como negociar e criar estratégias para realizar o seu trabalho e, ao mesmo tempo, garantir a sobrevivência física e emocional necessária para encarar situações onde a pobreza e a violência são prevalentes? "Vai conversar com o

${ }^{4}$ As frases dos trabalhadores foram retiradas das sessões grupais e do relatório final validado. 
paciente e absorve tudo de ruim e tem que guardar tudo. Fica acumulado, não pode contar o caso para os outros, fica com a carga. Para separar o problema a gente deveria ter apoio psicológico"; "A gente vai definhando junto com eles (usuários)"; "Como a gente fica doente de trabalhar com o povo doente!".

\section{Credibilidade versus invasão da privacidade dos moradores da comunidade}

Ao morar na comunidade e adentrar a privacidade de seus vizinhos, os ACS acabam, mesmo contra sua vontade, gerando uma via de mão dupla aos olhos dos usuários. Ou seja, o fato de morarem no mesmo bairro, entrarem nas casas e conhecerem não só as demandas de saúde, mas também a realidade socioeconômica, as questões familiares, de relacionamento interpessoal (aspectos íntimos), promove o estabelecimento de relações peculiares com essas pessoas. Sua vida social acontece nos mesmos espaços que a dos seus clientes, e tudo o que fazem torna-se de conhecimento de todos. "Você não pode a ir a lugar algum, vem bater na porta da sua casa, na feira, perde a privacidade. É como artista" (ACS fala rindo da própria colocação. O grupo todo ri).

Conquistar a credibilidade da comunidade acaba sendo entendido, por muitos usuários, como sinônimo de coleguismo, de amizade, o que faz com que se sintam no direito de compartilhar da privacidade do ACS, sem considerar tal fato uma invasão. O ACS é "par do povo". "A gente faz parte do povo". "[Tenho] medo do usuário descobrir onde moro porque no próximo problema batem na sua porta".

O não reconhecimento social do papel profissional que os agentes ocupam se reflete na privacidade dos usuários do serviço de saúde, pois muitos moradores os procuram para saber da vida alheia, como se fossem 'fofoqueira de plantão' em tempo integral. "Um queria saber por que o outro tá passando no posto. Tem as fofoqueiras de plantão no portão perguntando ou querendo falar de outros moradores"; "Vizinho que quer saber o que tem na casa do outro. Como ela está com o marido? Eu saio da casa dela e minha memória apaga".

Outro aspecto relacionado com a exposição que vivenciam diz respeito à violência local. Referem sentir medo de alguns usuários saberem onde moram e, pensando em segurança, não solicitam, em alguns casos, a intervenção da Polícia ou do Conselho Tutelar. "A gente não devia morar na comunidade. Tranco meu filho, me tranco com medo"; "O povo da favela quer matar o ACS porque o paciente morreu esperando a consulta. Imaginou isso, tenho filho e estuda na mesma escola que os filhos deles!"; "Ligam na minha casa e falo que não estou. Já fiz curso de telefonista, hoje é útil".

\section{Privacidade do ACS e sua família}

Referem que o fato de residirem na microárea tem gerado constrangimentos a si e seus familiares, pois os usuários os assediam em locais públicos ou em suas residências em qualquer horário, e sequer respeitam o fato de estarem acompanhados de seus familiares: "Somos agentes 24 horas. Não tem folga, não tem final de semana, em todos os momentos na comunidade perguntam tudo, eles não separam".

Quantas horas se trabalha por dia? Onde inicia e termina a jornada? É possível fechar a porta de casa e não atender aos vizinhos? "Ligam-me nas férias pra saber de prontuário. Você não tem dinheiro pra viajar nas férias e as colegas trazem guias, paciente vem pedir vaga"; "Saio de casa cumprimentando todo mundo, nossos filhos ficam mal-humorados, não tenho privacidade; (os filhos reclamam:) minha mãe não é mais minha, é mãe de todo mundo"; "A mulher me tirou do sério. Veio no final de semana na minha casa e falou: Você não tem boa vontade! Vai deixar eu morrer que nem a Maria lá de cima! Não escapa disso, por mais que ponha limites".

Além disso, devido ao fato de seus familiares também pertencerem àquela comunidade, por vezes, passam constrangimentos quando são acusados de saber e divulgar informações que os usuários contaram ao ACS. Mesmo que a informação tenha 'vazado' de outra forma, o ACS e seus familiares são, em muitos casos, os primeiros a serem acusados. "Você mora aqui; o médico vem aqui de vez em quando e 
daí? Se vazar o problema, ninguém vai sofrer nada com isso, só você que mora aqui"; "O conselho tutelar vem e vai embora, eu estou lá - os vizinhos culparam a agente de ter denunciado a família".

Essa situação de exposição, sobre a qual não têm controle, Ihes gera sentimentos de medo. Referem que buscam estratégias de proteção para minimizar a invasão à sua privacidade, mas essas nem sempre funcionam: "Muitas pessoas acham natural procurar a gente sempre que precisam de algo"; " "Faço questão de trabalhar com uniforme, fora do horário eu mostro que estou sem o uniforme"; " Eu entro no portão de casa olhando pros lados pra ver se tem paciente pra ver onde eu moro".

Outra questão diz respeito à privacidade de sua família. Quando têm algum problema de saúde e necessitam de atendimento médico são controlados pela comunidade. Os agentes chateiam-se de não poderem usufruir do serviço de saúde para si e sua família sem ouvir reclamações de que estão sendo privilegiados. "Todo mundo fica doente, mas a família do agente não tem direito a atendimento. Vai colocar de novo alguém da sua casa! É minha sogra depois das cinco horas, antes ela é uma usuária como outro qualquer"; "O ACS continua sendo povo, pior que povo, pois o povo consegue atendimento e nós não".

\section{Relação com a comunidade e com o serviço de saúde como morador da região}

No cotidiano de trabalho, a relação do agente com a comunidade está permeada pelo processo de construção da credibilidade, portanto, tiveram de construir novas relações sociais: como sujeitos pertencentes a essa comunidade e como trabalhadores do serviço de saúde. Referem que passar de usuário a ACS foi um processo difícil, e que, agora, convivem com uma grande questão: como se relacionar como ACS? E como morador da comunidade, colega, amigo? "Você fica mal educado. Eu estava no supermercado e o paciente vem perguntar do exame, fiquei grosseira, não era grosseira".

Ao residir na mesma comunidade na qual trabalha, o agente estabelece relações diversas: relações profissionais e pessoais, relações de agente de saúde e de vizinho, relações de quem orienta quanto aos cuidados com a saúde, e de quem frequenta os mesmos espaços sociais que os usuários. "Fui numa festa e tinha uma paciente diabética se enchendo de bolo! Na segunda-feira ela foi no posto e perguntei se $o$ bolo estava bom [...]".

Referem que as relações ficam confusas no contato cotidiano com a comunidade. "Não quero saber de sua vida particular, mas (pausa) eu quero e preciso saber de sua vida particular". "Uma ACS era testemunha de Jeová e jogaram água quente nela, depois foi fazer visita como ACS na mesma família"; "Como encontrar com essas pessoas em outros momentos fora do trabalho e reagir normalmente sabendo que ela está doente e necessitando de exame ou tratamento?".

Um último aspecto a ser destacado é que o processo de construção da credibilidade é dinâmico e precisa ser constantemente reassegurado (Lancman et al., 2007). A manutenção desta credibilidade está diretamente associada à resolução das problemáticas demandadas pelos usuários, o que, no entanto, é dificultado por aspectos relacionados à estruturação do serviço e à inoperância do sistema de saúde em atender as necessidades da comunidade. A unidade de saúde não consegue atender toda a demanda existente, assim, faltam consultas médicas, exames, medicamentos. Além disso, existe a dificuldade em conseguir consultas com especialistas, exames de alta complexidade, entre outros. Ou seja, o sistema de referência e contrarreferência, que deveria dar suporte às ações do PSF, não desempenha tal papel de maneira satisfatória. "O que você tá fazendo aqui não serve pra nada. Conseguiu? Arrumou uma vaga? Isto é estressante e humilhante!"; "A gente marca consulta e tem que priorizar quem vai ser atendido. Como explicar isso pro paciente? Não tem como você ver o que é mais urgente".

Referem que a necessidade de, por vezes, precisarem mentir, ou darem um jeitinho para manterem a credibilidade da comunidade, gera sofrimento, por saberem antecipadamente que parte das demandas e daquilo que prometem não será atendido: "A gente não consegue cumprir o que promete, por isso mentimos". "Fomos avisar a comunidade que o posto vai atender e não atende. Eu tenho que falar para as pessoas que tem isso ou aquilo e a gente tem que rir dessa palhaçada!".

Como estabelecer uma relação de confiança quando sabem que o serviço que estão oferecendo ao cidadão é precário ou não está disponível? Como prometer o mesmo serviço que já não conseguiram cumprir? 
A falta de resolutividade provoca um sofrimento adicional aos agentes devido ao contato próximo, ininterrupto, e ao vínculo que estabelecem com a comunidade, o que os faz sentirem-se responsáveis pelos seus clientes, além de testemunharem e partilharem as consequências dessa inoperância no agravo da saúde e sofrimento dos familiares. Frases como 'eu matei meu paciente' surgiram diversas vezes nas sessões grupais.

\section{Discussão e conclusões}

Segundo documentos do Ministério da Saúde, no trabalho prescrito, a atribuição principal do ACS é ser um agente educador, com o objetivo de transmitir informações que melhorem a capacidade de enfrentamento dos problemas de saúde por parte da população. Contudo, no cotidiano, os agentes tornam-se depositários dos anseios da comunidade, por serem os representantes do sistema de saúde com mais frequente e íntimo contato com os usuários. O trabalho real efetiva seu papel de agente educador, ao considerá-lo importante para desenvolver a capacidade de a população cuidar de sua saúde, porém não o suficiente para que possa atender às demandas da comunidade. A defasagem e as contradições entre trabalho real e prescrito têm sido apontadas, em diversos estudos de PDT, como fator que contribui para a invisibilidade do trabalho realizado, e termina sendo um dificultador nos processos de reconhecimento e, consequentemente, de construção identitária (Dejours, 2004).

Na medida em que levar informação, ampliar o conhecimento da população e sua capacidade de enfrentamento dos problemas de saúde não é suficiente, o agente se vê imbricado em um trabalho que vai além de suas competências e possibilidades de resolução. Como seu trabalho não atende às demandas da população, esta não reconhece a qualidade das ações do ACS, nem os esforços que faz para realizá-las, independentemente dos resultados alcançados, e exige dele uma atuação efetiva, resolutiva. Essa cobrança é fortalecida pelo constante contato que os moradores da comunidade mantêm com o agente, ao frequentarem os mesmos espaços sociais e terem acesso à sua casa, e ao considerarem ele vizinho, antes mesmo de ACS.

Os resultados referentes à construção da credibilidade são corroborados com a literatura científica sobre ACS, no que se refere à importância do contato cotidiano, das visitas domiciliares e da conversa com a população, para desenvolver o trabalho e o vínculo com os usuários (Spiri, 2006; Lunardelo, 2004; Nunes et al., 2002). No entanto, ressaltam que o contato é construído no trabalho diário, na aproximação e na constante busca de estabelecer e manter a credibilidade perante a comunidade, em um processo que acontece gradualmente. Não é garantido a priori, mas, precisa ser conquistado, desenvolvido no cotidiano. Portanto, não é determinado pelo fato de morar ou não na própria região, e, segundo os dados obtidos, muitas vezes, pode até mesmo ser dificultado pela convivência. Tal argumentação torna-se importante quando se pensa a obrigatoriedade que é imposta a esse profissional.

Esses dados contrapõem-se às idéias defendidas por Lunardelo (2004) quanto à proximidade física como geradora de vínculos com a comunidade e facilitadora no trabalho; e condizem quanto ao sofrimento do agente, decorrente da relação de igual que estabelece com a comunidade.

Estratégias adotadas pelo ACS, na realização do seu trabalho, objetivam, muitas vezes, encobrir falhas do sistema de saúde, situação que provoca conflitos nas relações com a comunidade. Como o agente depende da dinâmica das relações estabelecidas, mentir e constantemente ter de reafirmar a mentira, para, assim, adentrar a casa e a vida das pessoas, gera sofrimento durante o trabalho. Por morar na região, a mentira atinge a si próprio, na medida em que depende dessa mesma rede de serviços que é insuficiente para atender às suas necessidades e às de sua família.

A falta de cadência entre a demanda da população e a disponibilidade dos serviços, ou seja, o insuficiente suporte do sistema de saúde e a impossibilidade de que o usuário tenha acesso a outros níveis de atenção dificultam as relações de confiança, ocasionando: conflitos pessoais, instabilidade nas relações de trabalho, prejuízos à produção, à qualidade do trabalho e ao atendimento prestado.

O sofrimento decorre, então, da constatação da impossibilidade de solucionar as questões apresentadas e do contato constante e prolongado com essa população. Reflete a frustração vivenciada 
pelo agente devido: à dedicação que dispensa ao trabalho, à disponibilização do tempo, da energia física e psíquica, e à impossibilidade de resolução dos problemas.

A falta de resolutividade, aliada à exposição excessiva dos ACS, é expressa em desqualificação do trabalho, e provoca consequências na operacionalização desse trabalho - que depende de relações de confiança - e na saúde mental desses agentes. A inivisibilidade dos esforços realizados e a falta de reconhecimento dos usuários enfraquecem as defesas psíquicas dos agentes e a possibilidade de transformação das relações de sofrimento em prazer por meio do fortalecimento identitário e da realização de si, comprometendo, em última instância, o sentido do trabalho realizado. As consequências desse ciclo (falta de reconhecimento - enfraquecimento identitário - e perda do sentido do trabalho) têm sido apontadas em diversos estudos de PDT como fonte de sofrimento patogênico e desestruturação das relações de trabalho (Dejours, 2004).

Destacamos que, por ser um trabalho novo, a identidade profissional dos ACS ainda está em construção, agudizando a influência do reconhecimento dos esforços realizados no processo de construção identitária. Destaca-se que o reconhecimento social no campo do trabalho ocorre de forma indireta em relação à atividade. Portanto, "o que o sujeito procura fazer reconhecido é o seu fazere não o seu ser [...]. Somente depois de ter reconhecida a qualidade do meu trabalho é que posso, posteriormente, repatriar esse reconhecimento para o registro da identidade" (Dejours, 1999, p.21).

É relevante o sofrimento gerado pelas falhas do sistema, porém não acreditamos ser essa a única matriz do sofrimento relatado pelo agente, e sim um agravante. O fato de morar na região, poder ser interpelado a qualquer hora do dia e da noite, na rua, no supermercado, na feira, enfim, nos espaços sociais que compartilha com a comunidade, expõe o agente, constantemente, ao assédio das pessoas. Portanto, o sofrimento que ACS relata é agravado: pelo fato de residir na comunidade, pelo aumento do contato, da exposição e da perenidade que isso gera, e pela impossibilidade de se distanciar.

O espaço de trabalho que é público se confunde com o espaço do viver e conviver, que deveria ser privado, mas que, nesse caso, também se torna público. Essa hiperexposição e sobreposição da vida privada e da vida pública terminam criando situações de extrema porosidade, e sendo um fator de sofrimento psíquico adicional.

Os relatos dos agentes evidenciam que o fato de morarem na comunidade não lhes garantiu acesso às casas. Ao adentrarem a intimidade dos usuários, que são também seus vizinhos, acabam expondo sua vida particular, na medida em que moram na região e, portanto, também têm o título de 'vizinhos'. Da mesma forma que adentram a intimidade das pessoas, ficam expostos na sua própria vida privada. A exposição não somente é de sua vida particular, como também de sua família, residência, hábitos cotidianos e intimidade.

Segundo Arendt (2005), o termo público denota dois fenômenos que estão intimamente correlacionados. O primeiro refere que tudo o que vem a público, ou torna-se público, pode ser visto e ouvido por todos, tem a maior divulgação possível e constitui-se na realidade. O segundo fenômeno é que o termo público significa o próprio mundo, na medida em que é comum a todos nós e diferente do lugar que nos cabe dentro dele. A esfera pública refere-se ao mundo comum, a algo ou aquilo que pode ser visto sob diversos aspectos e perspectivas, e onde nada pode ser ocultado. Assim, o aspecto negativo do que é público é a privação da liberdade. Portanto, podemos concluir que morar e trabalhar na mesma comunidade compromete as relações público-privadas e a liberdade desses trabalhadores.

Nunes et al. (2002), ao estabelecerem a valorização dos aspectos afetivos, na relação do agente com a comunidade, como fator responsável pela exposição da intimidade de ambos, não consideram, em seu estudo, o fator 'morar na comunidade'. Os resultados encontrados mostram que esse fator promove a valorização dos aspectos afetivos, na medida em que, para a população, o agente compartilha daquela mesma realidade e encontra-se em tempo integral acessível à comunidade, mesmo não sendo o termo acessível sinônimo de disponível. Essa exposição corrobora com a discussão acerca do sofrimento no trabalho.

O trabalho atinge outros espaços da vida cotidiana do sujeito e, portanto, deve ser visto como um "continuum que se estende para além de seu espaço restrito e influencia outras esferas da vida" (Lancman, Uchida, 2003, p.85). A Psicodinâmica do Trabalho tem demonstrado que a exposição psíquica, quando excessiva, tal como vivenciada pelos ACS, provoca sofrimentos no trabalho, que 
passam a permear todas as demais esferas da sua vida, contaminando as relações pessoais, afetivas e familiares (Dejours, 2004).

Os ACS aprenderam a desenvolver estratégias (para fazer o trabalho acontecer, se proteger da exposição excessiva e tornar o sofrimento vivenciado suportável) que refletem uma engenhosidade desse trabalhador, um jeito particular, individual e coletivamente construído, para permitir o cumprimento das atividades. Essa inteligência, denominada, pela PDT, de inteligência da prática, antecede a consciência que os trabalhadores têm dela e garante uma engenhosidade da ação e do trabalhar (Dejours, 2004). Resulta e é desenvolvida no fazer, nas ações cotidianas, dentre as quais destacamos: trabalhar de uniforme; tentar delimitar seu horário de atuação; entrar ou sair às escondidas de casa para não ser identificado; disfarçar a voz ao telefone; buscar distanciar a vida pessoal e familiar da vida no trabalho, tentando impedir que o trabalho concretamente invada o tempo do não trabalho. Procuram, ainda, criar artifícios para ajudarem a comunidade e suprirem as falhas do sistema de saúde: usam de relações pessoais para anteciparem ou viabilizarem atendimentos, organizam coletas de dinheiro, roupas e medicamentos, entre outras. Algumas dessas estratégias são exemplos das estratégias defensivas, definidas por Dejours (2004) como estratégias necessárias, desenvolvidas pelos trabalhadores para se protegerem do sofrimento excessivo vivenciado.

O maior envolvimento emocional previsto para as equipes do PSF, pelos gestores que idealizaram esse Programa, objetiva humanizar o trabalho e diminuir a distância entre serviço de saúde e comunidade, sendo, portanto, um aspecto positivo e inovador. No entanto, para os ACS, ainda que desenvolvam estratégias para amenizar o sofrimento gerado pelo contato intenso e prolongado, o fato de morarem na comunidade agudiza essa imersão, evidenciando a contaminação do tempo do não trabalho, tal como descrita por Dejours (2004).

É necessário salientar que o trabalho dos ACS não é composto somente por decepções e frustrações. Muitas vezes, conseguem resolver e ajudar as famílias com seu trabalho. Logo, a mesma fonte que gera o sofrimento também é a de prazer e reconhecimento da população. O ACS representa, também, a via de acesso ao médico que salva vidas e ajuda a minorar as doenças que as pessoas sofrem. Sua função de elo não tem só o sentido negativo. É, ao mesmo tempo, positivo, o que confere aos agentes status junto à comunidade em que vivem.

A discussão e partilha das dúvidas e anseios com pares permite a construção de consensos, de soluções partilhadas e o estabelecimento de relações de cooperação. Partilhar o sofrimento é também uma possibilidade de fortalecer os mecanismos defensivos, pois permite aos trabalhadores minimizarem o sofrimento vivenciado, criarem redes de apoio e estabelecerem acordos éticos que, por vezes, os auxiliam a encontrar soluções e diminuir a solidão diante de problemas que não podem resolver. Atinge-se, assim, outra dimensão do trabalho, que parte do individual para o coletivo, e viabiliza-se a construção de novos acordos e regras que diminuem a solidão e contribuem positivamente na realização do trabalho real. Dessa forma, constituem-se aspectos do trabalhar do ACS e se obtem mais informações sobre esse trabalho, que podem se transformar em conhecimento e contribuição à saúde dos trabalhadores ao serem incorporadas no processo de reformulação do trabalho prescrito.

Ao refletirmos sobre o material analisado, consideramos que, apesar de se referir a um estudo de caso, acreditamos que os resultados obtidos são generalizáveis a outros agentes comunitários de saúde, por ser o aspecto 'morar na comunidade' algo comum a todos os trabalhadores dessa profissão.

O presente estudo contribui, ainda, com o avanço da pesquisa em Psicodinâmica do Trabalho, pela especificidade da situação estudada. A porosidade e a exposição excessiva entre trabalhadores e usuários, apesar de ocorrerem em outros tipos de trabalho, aqui são evidenciadas pelo morar e o trabalhar na mesma comunidade. Dessa forma, apesar da particularidade da situação de trabalho estudada, esta propicia a compreensão de aspectos existentes em outras atividades, mas que, por não ocorrerem em tal intensidade, não são tão visíveis.

O trabalho é uma ação, mas dependendo de sua organização, impede o indivíduo de pensar a racionalidade dessa ação, gerando, concomitantemente, uma limitação na capacidade de se pensar. Dejours propõe, então, por meio da PDT, o exercício da reflexão coletiva, que supõe uma ação destinada à apropriação de uma inteligibilidade comum, regida pela intercompreensão de acordos e normas, produção de novas regras do trabalho e da própria profissão. A criação de um espaço público 
de deliberação, onde as pessoas possam falar e se escutar, permite que a transformação da organização do trabalho ocorra. A confrontação de opiniões sobre o trabalho promoverá o pensar individual e/ou coletivo. Se o trabalhador é capaz de pensar o trabalho, elaborar essa experiência ao falar, simbolizar o pensamento e gerar interpretação, tem a possibilidade de negociar, buscar novo sentido partilhado, transformar e fazer a organização do trabalho evoluir (Lancman, Uchida, 2003).

\section{Colaboradores}

Os autores Tatiana de Andrade Jardim e Selma Lancman participaram, igualmente, de todas as etapas de elaboração do artigo.

\section{Referências}

ARENDT, H. A condição humana. 10.ed. Rio de Janeiro: Forense Universitária, 2005.

BRASIL. Ministério da Saúde. Portaria n.648. Brasília, 2006. Disponível em: <http:// dtr2004.saude.gov.br/dab/legislacao.php>. Acesso em: 8 fev. 2008.

CEDEC. Inquérito com usuários e profissionais, percepção dos gestores e estudos sobre o trabalho no PSF. São Paulo: Consórcio Medicina USP, 2006 (Cadernos de Atenção Básica, estudos avaliativos, 3).

DEJOURS, C. Addendum - da psicopatologia à psicodinâmica do trabalho. In: LANCMAN, S.; SZNELWAR, L. (Orgs.). Christophe Dejours: da psicopatologia à psicodinâmica do trabalho. Brasília/Rio de Janeiro: Paralelo15/Fiocruz, 2004. p.47-104. Conferências brasileiras. São Paulo: FUNDAP/FGV, 1999

HELOANI, R.; LANCMAN, S. Psicodinâmica do trabalho: o método clínico de intervenção e investigação. Rev. Prod., v.14, n.3, p.77-86, 2004.

LANCMAN, $S$. et al. Un agent de santé communautaire: un travail où I'on s'expose. Rev. Int. Psychopathol. Psychodynamique Travail, v.17, p.97-124, 2007.

LANCMAN, S.; JARDIM, T.A. O impacto da organização do trabalho na saúde mental: um estudo em psicodinâmica do trabalho. Rev. Ter. Ocup. Univ. São Paulo, v.15, n.2, p.84-96, 2004.

LANCMAN, S., UCHIDA, S. Trabalho e subjetividade. Cad. Psicol. Soc. Trab., v.6, p.7788, 2003.

LUNARDELO, S.R. O trabalho do agente comunitário de saúde nos núcleos de saúde da família em Ribeirão Preto. 2004. Dissertação (Mestrado) - Escola de Enfermagem, Universidade de São Paulo, Ribeirão Preto. 2004.

MOLINIER, P. Psicodinâmica do trabalho e relações sociais de sexo: um itinerário interdisciplinar 1988-2002. Rev. Prod., v.14, n.3, p.14-26, 2004.

NUNES, M.O. et al. O agente comunitário de saúde: construção da identidade desse personagem híbrido e polifônico. Cad. Saude Publica, v.18, n.6, p.1636-46, 2002.

SILVA, J.A., DALMASO, A.S.W. Agente comunitário de saúde: o ser, o saber, o fazer. Rio de Janeiro: Editora Fiocruz, 2002. 
SPIRI, W.C. A identidade do agente comunitário de saúde - uma abordagem fenomenológica. Cienc. Saude Colet., 2006. Disponível em: <http:// www.abrasco.org.br/cienciaesaudecoletiva/artigos>. Acesso em: 2 dez. 2007.

TOMAZ, J.B.S. O agente comunitário de saúde não deve ser "super-herói". Interface Comunic., Saude, Educ., v.6, n.10, p.84-90, 2002.

JARDIM, T.A.; LANCMAN, S. Aspectos subjetivos de vivir y trabajar en la misma comunidad: la realidad vivida por el agente comunitario de salud. Interface Comunic., Saúde, Educ., v.13, n.28, p.123-35, jan./mar. 2009.

El Agente Comunitario de Salud (ACS) es el eslabón entre comunidad y sistema de salud en el Programa Salud de la Familia (PSF), el único trabajador que reside obligatoriamente en la comunidad donde trabaja. Su trabajo se pauta en el contacto directo, contínuo e ininterrupto con la comunidad. Este artículo discute el proceso de construcción y manutención de la credibilidad de los agentes en las relaciones con la comunidad y los factores subjetivos resultantes de la congruencia entre vivir y trabajar. Se ha utilizado la metodología propuesta en Psicodinámica del Trabajo con ACS de Pirituba, estado de São Paulo, Brasil. Se concluye que los agentes experimentan constreñimiento en el trabajo a causa de pertenecer a la misma comunidad en la que desempeñan su papel profesional y que el funcionamiento del PSF y la precariedad de los demás niveles del sistema de salud son fuente de sufrimiento adicional. Esta porosidad entre trabajar y vivir en la misma comunidad expone excesivamente a los trabajadores y hay elevada contaminación de tiempo de no trabajo.

Palabras clave: Agente Comunitario de Salud. Salud del trabajador. Condiciones de trabajo. Salud mental y trabajo. Investigación cualitativa. 